\title{
Trajectories of body mass index, from adolescence to older adulthood, and pancreatic cancer risk; a population-based case-control study in Ontario, Canada
}

\author{
Vanessa De Rubeis ${ }^{1}$ Michelle Cotterchio ${ }^{2,4}$ - Brendan T. Smith ${ }^{3,4}$. Lauren E. Griffith ${ }^{1}$ Ayelet Borgida ${ }^{5}$ \\ Steven Gallinger ${ }^{5,6} \cdot$ Sean Cleary ${ }^{7,8} \cdot$ Laura N. Anderson $^{1,9}$
}

Received: 19 March 2019 / Accepted: 15 June 2019 / Published online: 22 June 2019

(c) The Author(s) 2019

\begin{abstract}
Purpose Pancreatic cancer has the highest fatality rate of all cancers. Adulthood obesity is an established risk factor for pancreatic cancer; however, life-course obesity is not well understood. The aim of this study was to evaluate the association between body mass index (BMI) trajectories throughout the life-course and pancreatic cancer risk.

Methods A population-based case-control study was conducted (2011-2013) in Ontario, Canada. Cases were recruited from the Ontario pancreas cancer study $(n=310)$ and controls from the Ontario cancer risk factor study $(n=1258)$. Questionnaires captured self-reported height and weight at four timepoints (adolescence, $20 \mathrm{~s}, 30-40 \mathrm{~s}, 50-60 \mathrm{~s}$ ). BMI trajectories were identified using latent class growth mixture modeling. Odds ratios (OR) and 95\% confidence intervals (CI) were estimated from multivariable logistic regression.

Results Five BMI trajectories were identified: stable-normal weight (38.9\%), progressively overweight (42.2\%), persistent overweight (12.6\%), progressive obesity (4.2\%), and persistent obesity (2.1\%). The persistent overweight (OR $=1.55 ; 95 \%$ CI $1.02,2.39)$ and progressive obesity trajectories $(\mathrm{OR}=1.49 ; 95 \% \mathrm{CI} 0.77,2.87)$ compared to stable-normal weight were associated with increased odds of pancreatic cancer. When BMI was evaluated separately the strongest associations with pancreatic cancer emerged in young and mid-adulthood.

Conclusion BMI trajectories characterized by overweight in early adulthood were associated with increased pancreatic cancer risk suggesting a life-course approach to disease risk.
\end{abstract}

Keywords Body mass index $\cdot$ Obesity $\cdot$ Trajectory $\cdot$ Life-course $\cdot$ Pancreatic cancer

\section{Introduction}

Electronic supplementary material The online version of this article (https://doi.org/10.1007/s10552-019-01197-9) contains supplementary material, which is available to authorized users.

Laura N. Anderson

ln.anderson@mcmaster.ca

1 Department of Health Research Methods, Evidence, and Impact, McMaster University, 1280 Main Street West, Hamilton, ON L8S4L8, Canada

2 Prevention and Cancer Control, Cancer Care Ontario, Toronto, ON, Canada

3 Public Health Ontario, Toronto, ON, Canada

4 Dalla Lana School of Public Health, University of Toronto, Toronto, ON, Canada
Pancreatic cancer has the highest fatality rate of all cancers, with a 5-year survival rate of $8 \%$ [1]. The age-standardized incidence rate has remained relatively stable, with an annual

5 Division of General Surgery, Toronto General Hospital, Toronto, ON, Canada

6 Lunenfeld-Tanenbaum Research Institute, Mount Sinai Hospital, Toronto, ON, Canada

7 Department of Surgery, University Health Network, University of Toronto, Toronto, ON, Canada

8 Division of Hepatobiliary and Pancreas Surgery, Mayo Clinic, Rochester, MN, USA

9 Child Health Evaluative Sciences, The Hospital for Sick Children Research Institute, Toronto, ON, Canada 
percent decrease of only $0.1 \%$ per year since 1992 [2]. Globally, pancreatic cancer is the 12th most common cancer [3]. Primary prevention is important since $80 \%$ pancreatic cancer cases are diagnosed at an advanced stage due to difficulties associated with early detection, and no available screening programs [4]. Despite the high fatality rate, pancreatic cancer only accounts for approximately $3 \%$ of all cancer cases, thus prospective population-based studies of this disease are very difficult [5]. Some of the well-established risk factors for pancreatic cancer are non-modifiable, including older age, genetics, and family history [6]. The most well-established modifiable risk factors that have been identified are obesity and smoking [6-8].

Overweight and obesity in adults, most often defined as body mass index (BMI) $>25 \mathrm{~kg} / \mathrm{m}^{2}$ [9], is strongly associated with pancreatic cancer [10-13] (RR: 1.43; 95\% CI 1.19, 1.72) [14]. Globally, the prevalence of overweight and obesity has increased from 23.3 to $34.7 \%$ from 1978 to 2004 [15]. An association between obesity or high BMI in early adulthood and increased pancreatic cancer risk has been noted [10, 16-19]. However, few studies have evaluated the impact of BMI before age $18[11,20]$ or life-course trajectories of body size [21] on pancreatic cancer risk. Song et al., found that those who were consistently heavy, or increasingly heavy throughout their life compared to those who were lean-stable had an increased mortality due to pancreatic cancer (Males: HR: 1.15 ; $95 \%$ CI 0.79 , 1.66; Females: HR: 2.15; 95\% CI 1.49, 3.12) [22]. Understanding the impact of BMI over the life-course and the possible role of obesity in childhood in relation to pancreatic cancer risk is important given that the prevalence of overweight and obesity in children and adolescents has exceeded 30\% [23, 24]. Further, children and adolescents with obesity have an increased risk of remaining obese throughout adulthood [25-28].

Despite the known association between obesity and pancreatic cancer risk, there is limited research assessing the impact of BMI trajectories across the life-course on pancreatic cancer risk. It is important to understand if there are sensitive periods across the life-course that differentially effect risk of pancreatic cancer. The primary objectives of this study were to identify trajectories of BMI over the life-course and to evaluate the association between these BMI trajectories from adolescence to older adulthood, and the risk of pancreatic cancer. The secondary objective of this project was to evaluate BMI during specific time periods of exposure in relation to odds of pancreatic cancer.

\section{Methods}

\section{Study design}

A population-based case-control study was conducted using cases from the Ontario pancreas cancer study (OPCS) and controls from the Ontario cancer risk factor study (OCRF) [29].

\section{Cases}

Pancreatic cancer cases were recruited between 2011 and 2013 by the OPCS. The OPCS was one of seven study sites contributing data on genetic and epidemiologic factors among pancreatic cancer cases to the multidisciplinary pancreatic cancer genetic epidemiology (PACGENE) Consortium [7]. Cases were identified from the Ontario Cancer Registry rapid-case ascertainment system (electronic pathology reports). This is a population-based registry that obtains information for all cancer cases in Ontario through computerized probabilistic record linkage of data from pathology reports, regional cancer centers, hospital discharge and ambulatory care records, and Ontario death certificates. Men and women living in Ontario, who were diagnosed with pathologically confirmed adenocarcinoma of the pancreas or adenocarcinoma metastasis diagnosed by a physician (International Classification of Diseases for Oncology Third Edition codes C25.0-25.9, with 25.4 neuroendocrine pancreas excluded), were eligible for inclusion within the study. Cases with proxy respondents were excluded from this analysis. A total of 1310 cases of pancreatic cancer were diagnosed between February 2011 and January 2013, and of these, 314 were not mailed the study package ( 33 refused, 158 deceased or ineligible, and 123 unable to contact). From the 996 patients who were mailed the study package, a total of 414 (42\%) returned completed questionnaires, but 40 cases with proxy respondents and 64 cases missing BMI data at 3 or more time periods were excluded, leaving 310 cases included in the analysis. $84 \%$ of cases had data for BMI at all four timepoints.

\section{Controls}

Population-based controls were recruited through the OCRF in 2011. Controls were recruited using a modified random digit dialing procedure of households in Ontario and were frequency matched (3:1) on 5-year age and sex groups based on the expected distribution of cases. The OCRF identified 1995 eligible controls, $87 \%$ agreed to participate and were mailed the study package. The full epidemiologic questionnaire was completed by 1285 individuals (74\%). 27 participants were excluded due to missing BMI data at three or more time periods, leaving 1258 controls included within the analysis. $87 \%$ of controls had data for BMI at all four timepoints.

\section{Research ethics}

Research ethics approval for this study was obtained from the University of Toronto and Mount Sinai Hospital, Toronto, Canada. The protocol for the current secondary 
data analysis received research ethics approval from McMaster University, Hamilton, Canada.

\section{Data collection}

Cases and controls who were eligible for participation were mailed a study package containing four self-administered questionnaires: epidemiology, family history, allergy, and food (short 55-item) [29]. If no response was received within 2 weeks of mailing the study package, participants were sent a reminder postcard, followed by telephone follow-up. If there was no response after 10 weeks, the participant was sent a second package.

\section{Measurement of body mass index}

Cases and controls were asked to report their height "Approximately how tall are you (without shoes on)?". Recall of body weight was asked for five distinct timepoints: adolescence, young adulthood (20 s), mid-adulthood (30-40 s), later adulthood (50-60 s) and current (for controls) or 1 year prior to cancer diagnosis (for cases). Selfreported recall of past weight has been noted to be a valid measure of true adiposity as it is highly correlated with prospectively collected data (pooled $\mathrm{r}=0.91 ; 95 \%$ CI 0.91 , 0.92) [30-32]. For the four earlier age periods, study participants were asked the same questions, "Approximately how much did you weigh as a teenager?" [33-37]. BMI (kg/ $\mathrm{m}^{2}$ ) for each timepoint was calculated as weight in kilograms divided by height in meters squared. BMI cut-offs were determined using the World Health Organization guidelines, which considers a BMI greater than $25 \mathrm{~kg} / \mathrm{m}^{2}$ overweight and a BMI over $30 \mathrm{~kg} / \mathrm{m}^{2}$ obese [38]. We graphically inspected BMI at each timepoint to determine if there were any implausible values; none of the upper values were considered to be implausible (maximum BMI was 65), but there were three lower BMI values that were considered implausible and were changed to missing $(n=3)$.

\section{Measurement of other variables}

In general, exposures were assessed 2 years prior to cancer diagnoses for cases or 2 years earlier for controls. Variables associated with both the exposure (BMI) and the outcome (pancreatic cancer) were selected as potential confounders. These included: age, sex, education, race, family history of pancreatic cancer, cigarette smoking, alcohol intake, current physical activity (moderate and vigorous), and fruit, vegetable, and red meat intake. Diabetes and pancreatitis were identified as potential mediating variables and therefore were not included in the full model which adjusted for all confounders. Rather a third model was generated which included the full model plus diabetes and pancreatitis to determine the effect on BMI and pancreatic cancer risk. Data on covariates were collected through the epidemiology questionnaire. Cigarette smoking was categorized as never, current or former smoker. Alcohol was categorized as never, former, current light to moderate drinker (1-20 drinks/week), and current heavy drinker ( $>21$ drinks/week). Leisure and work physical activity from all sources were measured separately for moderate and vigorous activity levels. Moderate activity included bowling, golf, light sports, or taking long walks, whereas vigorous physical activity included jogging, swimming, aerobics, or strenuous sports.

\section{Defining BMI trajectories}

Latent Class Growth Mixture Modeling (LCGMM) [39] was used to define life-course BMI trajectories using PROC TRAJ [40] in SAS software version 9.4 [41]. This groupbased trajectory modeling procedure identifies subgroups of people among the whole study population who share similar underlying trajectories of BMI over the life-course. Data on BMI from teenage years, young adulthood (20 s), midadulthood (30-40 s), and late adulthood (50-60 s) contributed to defining the trajectories. Current BMI was not used in the development of trajectories since we only had access to crud age groups and did not have exact current age due to privacy concerns.

Based on a priori knowledge [21, 42] we tested the fit of models with up to seven trajectories. Model fit statistics using the Bayesian information criterion (BIC) were used to identify the best number of trajectories and the significance of polynomial terms (linear, quadratic or cubic). Once the final model was determined, the posterior probabilities and percentage of group memberships were assessed to further assure the most optimal model was chosen. A 5-class model with a quadratic structure fit the data best. Names were assigned to each of the five trajectories based on visual inspection of the trajectory plots. Sensitivity analyses were conducted to evaluate trajectories among the controls only and a similar 5-class model fit best. Participants were assigned to a trajectory based on their posterior probability. The mean posterior probability for each group exceeded the recommended 0.70 cut-off [39]. Although it is recommended that each group should hold at least 5\% group membership [43], we observed one group that consistently had $<5 \%$ of our sample and this group continued to emerge even when the number of classes was reduced. Upon visual inspection of the trajectory plots it was apparent that this group represented a unique class and was retained despite the small sample size. 


\section{Statistical analysis}

Descriptive analyses were reported including frequency and percent for cases and controls for all variables. All statistical analyses were conducted using SAS software 9.4 [44]. Unconditional multivariable logistic regression was used to estimate adjusted odds ratios (OR) with $95 \%$ confidence intervals $(\mathrm{CI})$ for BMI at individual timepoints and BMI trajectories across the life-course and pancreatic cancer risk. Conditional logistic regression was not used since frequency matching was used (e.g., not individual matches), but matching factors were included in all analyses. Results are presented for three models: 1) a parsimonious model adjusted only for age and sex; 2) a fully adjusted model that included age, sex, and all potential confounders; and 3) a model that included age, sex, all potential confounders plus two potential mediators (diabetes and pancreatitis). All covariates were controlled for in the model as described in Table 1, which the exception of smoking status which was included in the model as ever/former/current, and alcohol consumption which was included as ever/never.

Selected characteristics of the population-based controls participating in the OCRF study were compared to national population-based data from the 2011 Canadian Community Health Survey (CCHS) to determine how well the controls came from the source population as the cases. Survey data were used from the $2011 \mathrm{CCHS}$ for adults aged 40 to 90 living in Ontario.

\section{Results}

Table 1 provides the frequencies by case and control status and the age group and sex-adjusted OR for selected subject characteristics (some of which has been published previously $[29,45]) .53 \%$ of cases and controls were males, and $34 \%$ of cases and $25 \%$ of controls were over the age of 70 . Majority of participants were Caucasian (91\%), and more than half of both cases and controls had a highest education of a high school diploma or less. As shown previously in this study [29], family history of pancreas cancer, heavy alcohol consumption, cigarette smoking, current $\mathrm{BMI} \geq 30.0$, and non-Caucasian ethnicity were all associated with an increased odds of pancreatic cancer (see Table 1). Comparing the study data among controls only to the CCHS revealed that the data used in this study are representative of the general population of residents in Ontario (Fig. 1). The controls in our study had similar proportions for sex, diabetes, non-smokers, alcohol consumption patterns ( $>22$ drinks per week), however had slightly higher rates of obesity (BMI > 30). There were lower rates of non-Caucasian participants and those who attended post-secondary education among study controls in comparison to the provincial data. As expected, study controls were much older than the general population since they were frequency age-matched to cancer cases.

Five distinct trajectories of BMI across the life-course were identified (Fig. 2). The mean posterior probabilities were for groups $1-5$ were $0.91,0.87,0.89,0.90$ and 0.97 , respectively. We labeled these trajectories based on visual assessment; stable-normal weight (38.9\%), progressively overweight $(42.2 \%)$, persistent overweight (12.6\%), progressive obesity (4.2\%), and persistent obesity (2.1\%). Generating the trajectories among the controls only revealed the same five distinct trajectories of BMI and with approximately the same proportion of individuals; stable-normal weight $(37.3 \%)$, progressively overweight $(43.0 \%)$, persistent overweight $(12.8 \%)$, progressive obesity $(4.5 \%)$, and persistent obesity $(2.5 \%)$. Due to the small sample size in the persistent obesity trajectory a model with four trajectories was tested; however, the persistent obesity trajectory remained with a very small sample size. This trajectory consistently emerged throughout the various stages of model building.

Characteristics of the participants in each BMI trajectory among controls only are described in Table 2 . More than half of the participants in the stable-normal weight trajectory (63\%) and persistent obesity trajectory $(71 \%)$ were female. Consistent with the trajectories created including both cases and controls, the persistent obesity trajectory among controls only were considerably younger than other trajectories $(74 \%<60$ years of age). The progressive obesity trajectory had the greatest proportion of participants educated to high school or less $(70 \%)$, whereas the remaining trajectories had about half educated to this level. Across all trajectories, the proportion of participants who were an ever smoker was about half. For current alcohol consumption, the persistent obesity trajectory had the smallest proportion (29\%), whereas the remaining trajectories had proportions ranging from 48 to $62 \%$.

The association between each distinct trajectory and pancreatic cancer risk is reported in Table 3. Compared to the stable-normal weight trajectory (reference group), the progressively overweight (adjusted OR: 1.17; 95\% CI 0.86, 1.60), persistently overweight (adjusted OR: 1.72; 95\% CI $1.12,2.64$ ) and progressive obesity (adjusted OR: 1.70; 95\% CI $0.88,3.30$ ) all had increased odds of pancreatic cancer. The persistent obesity trajectory was inversely associated with odds of pancreatic cancer (adjusted OR: 0.24; 95\% CI $0.03,1.79$ ), but with a very wide confidence interval which limits interpretation of these results. The models adjusted for all potential confounders identified a priori (Model 2) were not substantially different from the models adjusted for age and sex only. Further adjustment for diabetes and pancreatitis (potential mediating variables) in Model 3 did not yield results that were substantially different from the 
Table 1 Age group and sexadjusted odds ratio estimates for pancreatic cancer risk factors among cases diagnosed in 20112013 and controls recruited in 2011, from Ontario, Canada

\begin{tabular}{|c|c|c|c|c|c|c|}
\hline \multirow[t]{2}{*}{ Characteristic } & \multicolumn{2}{|c|}{ Cases $(n=310)$} & \multicolumn{2}{|c|}{$\begin{array}{l}\text { Controls } \\
(\mathrm{n}=1,258)\end{array}$} & \multirow[t]{2}{*}{$\mathrm{OR}^{\mathrm{a}}$} & \multirow[t]{2}{*}{$95 \% \mathrm{CI}$} \\
\hline & $n$ & $\%$ & $n$ & $\%$ & & \\
\hline \multicolumn{7}{|l|}{ Age $(y)^{b, c}$} \\
\hline$<60$ & 79 & 26 & 444 & 35 & - & - \\
\hline $60-64$ & 65 & 21 & 282 & 20 & - & - \\
\hline $65-69$ & 58 & 19 & 220 & 17 & - & - \\
\hline$\geq 70$ & 104 & 34 & 312 & 25 & - & - \\
\hline Missing & 4 & 1 & 0 & 0 & & \\
\hline \multicolumn{7}{|l|}{ Gender $^{\mathrm{b}}$} \\
\hline Male & 164 & 53 & 662 & 53 & - & - \\
\hline Female & 146 & 47 & 596 & 47 & - & - \\
\hline \multicolumn{7}{|l|}{ Education $^{\mathrm{d}}$} \\
\hline College/university graduate & 129 & 42 & 577 & 46 & 1.00 & \\
\hline High school graduate or less & 180 & 58 & 680 & 54 & 1.14 & $0.88,1.47$ \\
\hline Missing & 1 & 0.3 & 1 & 0.1 & & \\
\hline \multicolumn{7}{|l|}{ Race } \\
\hline Caucasian & 265 & 85 & 1154 & 92 & 1.00 & \\
\hline Non-Caucasian & 44 & 14 & 104 & 8 & 1.77 & $1.20,2.60$ \\
\hline Missing & 1 & 0.3 & 0 & 0 & & \\
\hline \multicolumn{7}{|l|}{ Family history of pancreas cancer ${ }^{\mathrm{e}}$} \\
\hline No & 256 & 83 & 1144 & 91 & 1.00 & \\
\hline Yes & 33 & 11 & 49 & 4 & 3.03 & $1.90,4.83$ \\
\hline Don't know & 20 & 7 & 61 & 5 & & \\
\hline Missing & 1 & 0.3 & 4 & 0.3 & & \\
\hline \multicolumn{7}{|l|}{ Body mass index $\left(\mathrm{kg} / \mathrm{m}^{2}\right)^{\mathrm{f}}$} \\
\hline$<25.0$ & 102 & 33 & 402 & 32 & 1.00 & \\
\hline $25.0-<30.0$ & 109 & 35 & 519 & 41 & 0.86 & $0.63,1.17$ \\
\hline$\geq 30.0$ & 99 & 32 & 336 & 27 & 1.25 & $0.91,1.73$ \\
\hline Missing & 0 & 0 & 1 & 0.1 & & \\
\hline \multicolumn{7}{|l|}{ Alcohol intake ${ }^{g}$} \\
\hline Never & 107 & 35 & 406 & 33 & 1.00 & \\
\hline Former & 27 & 9 & 85 & 7 & 1.26 & $0.77,2.06$ \\
\hline Current & 173 & 56 & 756 & 60 & 0.82 & $0.59,1.14$ \\
\hline Light to moderate (1-20 drinks/wk) & 138 & 45 & 658 & 54 & 0.83 & $0.57,1.21$ \\
\hline Heavy $(21+$ drinks/wk $)$ & 29 & 10 & 72 & 6 & 1.60 & $0.98,2.64$ \\
\hline Missing & 3 & 1 & 11 & 1 & & \\
\hline \multicolumn{7}{|l|}{ Cigarette smoking } \\
\hline Never & 118 & 38 & 573 & 46 & 1.00 & \\
\hline Ever & 188 & 61 & 683 & 54 & 1.34 & $1.04,1.74$ \\
\hline$>0-<8.5$ pack years & 59 & 19 & 223 & 18 & 1.29 & $0.91,1.84$ \\
\hline $8.5-<22$ pack years & 57 & 18 & 231 & 19 & 1.24 & $0.87,1.77$ \\
\hline$\geq 22$ pack years & 66 & 21 & 220 & 18 & 1.46 & 1.03. 2.06 \\
\hline Missing & 10 & 1 & 2 & 0.1 & & \\
\hline \multicolumn{7}{|l|}{ Diabetes $^{\text {h }}$} \\
\hline No & 247 & 80 & 1090 & 87 & 1.00 & \\
\hline Yes & 63 & 20 & 159 & 13 & 1.61 & $1.16,2.24$ \\
\hline Missing & 0 & 0 & 9 & 1 & & \\
\hline \multicolumn{7}{|l|}{ Pancreatitis ${ }^{\mathrm{h}}$} \\
\hline No & 290 & 94 & 1236 & 98 & 1.00 & \\
\hline Yes & 20 & 6 & 14 & 1 & 5.72 & $2.82,11.61$ \\
\hline Missing & 0 & 0 & 8 & 1 & & \\
\hline
\end{tabular}


Table 1 (continued)

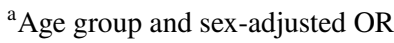

${ }^{b}$ No reported OR, controls frequency matched to cases

${ }^{\mathrm{c}}$ Age at pancreas cancer diagnosis for cases; age at questionnaire completion for controls

${ }^{\mathrm{d}}$ Highest level of education reached

${ }^{\mathrm{e}}$ Immediate blood relatives

${ }^{\mathrm{f}}$ One year prior to completion of questionnaire for both cases and controls

"Both cases and controls were asked to recall alcohol intake "approximately two years ago"

${ }^{\text {h}}$ Cases were asked about diagnosis "before one year ago"; controls were asked if ever diagnosed

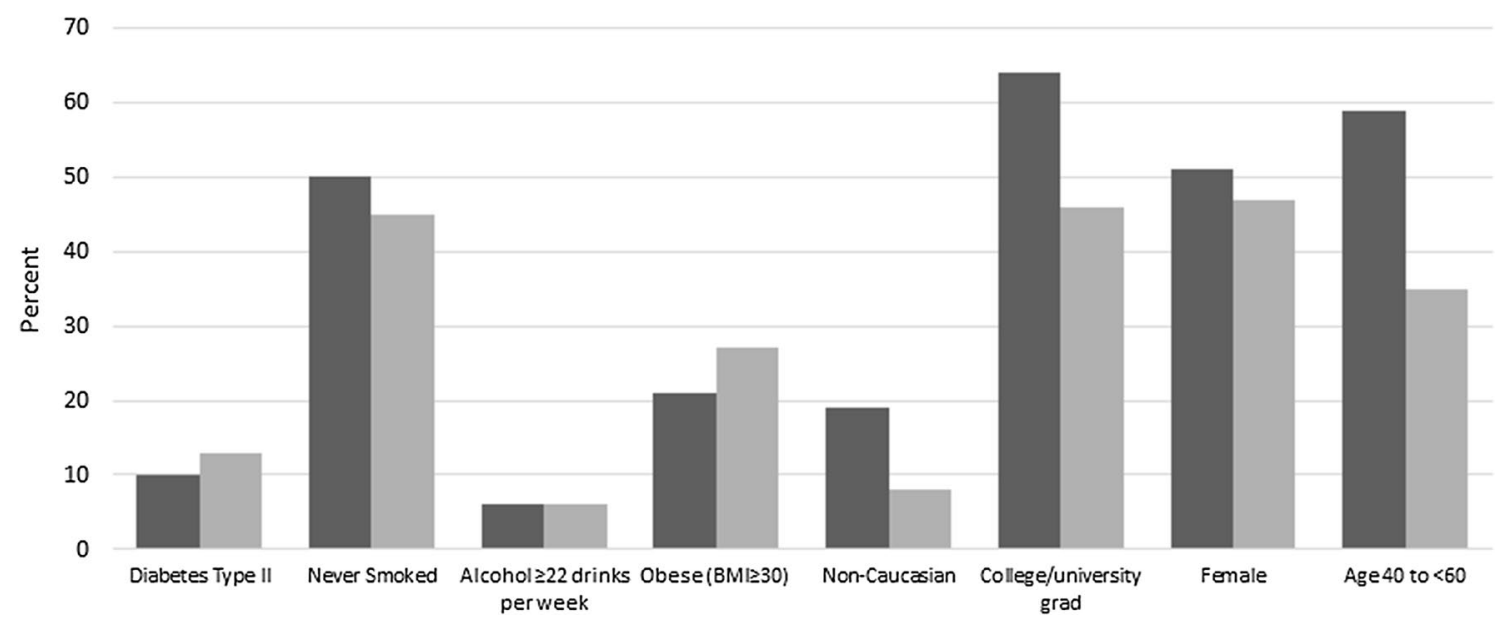

Fig. 1 Representativeness of Ontario cancer risk factor (OCRF) study controls compared to the Canadian community health survey (CCHS) for Ontarians aged 40-90 in 2011. The dark bars represent the Cana- dian community health survey (CCHS) data, whereas, the light gray bars represent the Ontario cancer risk factor (OCRF) data
Fig. 2 Latent BMI trajectories identified throughout the lifecourse $(n=1,568)$ among Cases Diagnosed in 2011-2013 and Controls Recruited in 2011, from Ontario, Canada. Class 1: Stable-normal weight trajectory is represented as the dotted line, with circular symbols. Class 2 : Progressively overweigh trajectory is represented as the solid line, with triangular symbols. Class 3: Persistent overweight trajectory is represented as the line with long dashes, with square symbols. Class 4: Progressive obesity trajectory is represented as the line with small dashes, with star symbols. Class 5: Persistent obesity trajectory is represented as the line with dashes and dots, with diamond symbols

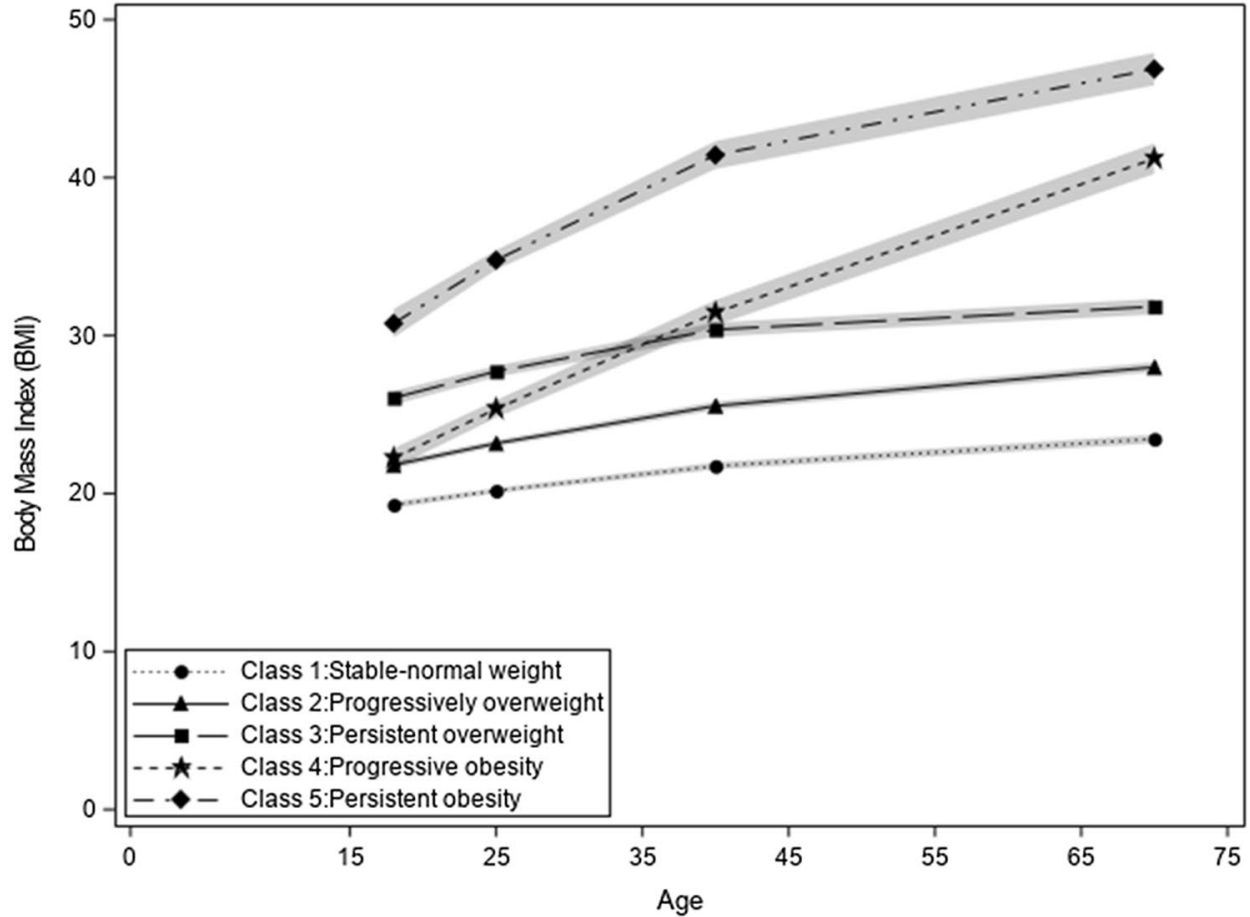


Table 2 Descriptive characteristics of the bmi trajectory groups among controls only, recruited in 2011, from Ontario, Canada ( $n=1,258)$

\begin{tabular}{|c|c|c|c|c|c|}
\hline Characteristics & $\begin{array}{l}\text { Class 1: stable- } \\
\text { normal weight } \\
(n=469) \%\end{array}$ & $\begin{array}{l}\text { Class 2: progressively } \\
\text { overweight }(n=541) \%\end{array}$ & $\begin{array}{l}\text { Class 3: persis- } \\
\text { tent overweight } \\
(n=161) \%\end{array}$ & $\begin{array}{l}\text { Class 4: progressive } \\
\text { obesity }(n=56) \%\end{array}$ & $\begin{array}{l}\text { Class 5: persistent } \\
\text { obesity }(n=31) \%\end{array}$ \\
\hline \multicolumn{6}{|l|}{$\operatorname{Age}(y)^{\mathrm{a}}$} \\
\hline$<60$ & 33 & 33 & 41 & 45 & 74 \\
\hline $60-64$ & 21 & 23 & 24 & 27 & 26 \\
\hline $65-69$ & 18 & 18 & 21 & 14 & 0 \\
\hline$\geq 70$ & 29 & 27 & 15 & 14 & 0 \\
\hline \multicolumn{6}{|l|}{ Sex } \\
\hline Female & 63 & 39 & 26 & 54 & 71 \\
\hline Male & 37 & 61 & 74 & 46 & 29 \\
\hline \multicolumn{6}{|l|}{ Education $^{\mathrm{b}}$} \\
\hline High school graduate or less & 51 & 54 & 57 & 70 & 52 \\
\hline College/university graduate & 49 & 46 & 43 & 30 & 48 \\
\hline \multicolumn{6}{|l|}{ Race } \\
\hline Non-Caucasian & 12 & 7 & 4 & 4 & 10 \\
\hline Caucasian & 88 & 93 & 94 & 96 & 90 \\
\hline \multicolumn{6}{|l|}{ Young adulthood (20 s) BMI } \\
\hline$<25.0$ & 99 & 79 & 6 & 43 & 0 \\
\hline $25.0-<30.0$ & 1 & 20 & 78 & 50 & 10 \\
\hline$\geq 30.0$ & 0 & 0 & 15 & 4 & 87 \\
\hline \multicolumn{6}{|l|}{ Mid-adulthood (30-40 s) BMI } \\
\hline$<25.0$ & 98 & 43 & 1 & 9 & 0 \\
\hline $25.0-<30.0$ & 1 & 53 & 53 & 20 & 0 \\
\hline$\geq 30.0$ & 0 & 2 & 45 & 70 & 97 \\
\hline \multicolumn{6}{|l|}{ Late adulthood (50-60 s) BMI } \\
\hline$<25.0$ & 69 & 9 & 1 & 0 & 0 \\
\hline $25.0-<30.0$ & 18 & 64 & 18 & 0 & 0 \\
\hline$\geq 30.0$ & 0 & 12 & 65 & 82 & 68 \\
\hline Age not reached & 12 & 11 & 16 & 18 & 32 \\
\hline \multicolumn{6}{|l|}{ Alcohol intake ${ }^{c}$} \\
\hline Current & 62 & 61 & 60 & 48 & 29 \\
\hline Former/never & 38 & 39 & 40 & 52 & 71 \\
\hline \multicolumn{6}{|l|}{ Smoking status } \\
\hline Ever & 53 & 55 & 56 & 59 & 54 \\
\hline Never & 47 & 45 & 44 & 41 & 46 \\
\hline \multicolumn{6}{|l|}{ Diabetes $^{\mathrm{d}}$} \\
\hline No & 93 & 86 & 83 & 68 & 68 \\
\hline Yes & 7 & 13 & 17 & 30 & 32 \\
\hline Missing & 1 & 1 & 0.6 & 2 & 0 \\
\hline \multicolumn{6}{|l|}{ Pancreatitis ${ }^{\mathrm{d}}$} \\
\hline No & 98 & 99 & 97 & 96 & 100 \\
\hline Yes & 1 & 1 & 2 & 4 & 0 \\
\hline Missing & 1 & 0.4 & 1 & 0 & 0 \\
\hline
\end{tabular}

${ }^{a}$ Age at pancreas cancer diagnosis for cases; age at questionnaire completion for control

${ }^{b}$ Highest level of education reached

'Both cases and controls were asked to recall alcohol intake "approximately two years ago"

dCases asked about diagnosis "before one year ago"; controls asked if ever diagnosed 
Table 3 Odds ratio estimates for latent BMI trajectory classes and pancreatic cancer among cases diagnosed in 2011-2013 and controls recruited in 2011, from Ontario, Canada

\begin{tabular}{|c|c|c|c|c|c|c|c|c|c|c|}
\hline \multirow[t]{2}{*}{ Trajectory classes } & \multicolumn{2}{|l|}{ Cases } & \multicolumn{2}{|l|}{ Controls } & \multicolumn{2}{|c|}{ Model 1} & \multicolumn{2}{|c|}{ Model 2} & \multicolumn{2}{|c|}{ Model 3} \\
\hline & $n=310$ & $\%$ & $n=1,258$ & $\%$ & $\mathrm{OR}^{\mathrm{a}}$ & $95 \% \mathrm{CI}$ & $\mathrm{OR}^{\mathrm{b}}$ & $95 \% \mathrm{CI}$ & $\mathrm{OR}^{\mathrm{c}}$ & $95 \% \mathrm{CI}$ \\
\hline Class 1: stable-normal weight & 117 & 38 & 493 & 39 & 1.00 & & 1.00 & & 1.00 & \\
\hline Class 2: progressively overweight & 128 & 41 & 534 & 43 & 1.07 & $0.81,1.43$ & 1.17 & $0.86,1.60$ & 1.15 & $0.84,1.58$ \\
\hline Class 3: persistent overweight & 349 & 16 & 149 & 12 & 1.55 & $1.04,1.32$ & 1.72 & $1.12,2.64$ & 1.63 & $1.05,2.53$ \\
\hline Class 4: progressive obesity & 14 & 5 & 51 & 4 & 1.35 & $0.72,2.54$ & 1.70 & $0.88,3.30$ & 1.51 & $0.77,2.99$ \\
\hline Class 5: persistent obesity & 2 & 0.7 & 31 & 3 & 0.36 & $0.08,1.53$ & 0.24 & $0.03,1.79$ & 0.22 & $0.03,1.70$ \\
\hline
\end{tabular}

${ }^{\mathrm{a}}$ Adjusted for age group and sex

${ }^{\mathrm{b}}$ Adjusted for age group, sex, race, alcohol consumption, smoking, vegetable consumption, fruit consumption, red meat consumption, current moderate physical activity, current vigorous physical activity, family history of pancreatic cancer

${ }^{\mathrm{c}}$ Adjusted for all variables in Model 2 plus pancreatitis, diabetes

fully adjusted ORs (Table 3). Sensitivity analyses were conducted removing the last timepoint for all participants in case of weight loss due to disease. When the last time point was removed five trajectories were identified that were very similar to the first three timepoints in the main results and the associations with pancreatic cancer were similar.

The associations between overweight and obesity at each time period over the life-course and pancreatic cancer risk are reported in Table 4. Obesity during young adulthood (adjusted OR: 1.29; 95\% CI 0.69, 2.43), and both overweight (OR: $1.27 ; 95 \%$ CI $0.93,1.74$ ) and obesity during mid-adulthood (OR: 1.49; 95\% CI 0.98, 2.28) were consistently associated with increased odds of pancreatic cancer in the minimally adjusted and fully adjusted models but were not statistically significantly different from 1.0. Conversely, overweight and obesity during later adulthood did not appear to be strongly associated with odds of pancreatic cancer. Although the sample size was small, and the confidence intervals were wide, these findings may possibly suggest that increased BMI in early life is a stronger risk factor for pancreatic cancer than exposure during later adulthood.

A stratified analysis was conducted by sex to evaluate possible effect modification. In the analyses stratified by sex, the persistent overweight trajectory, in comparison to the stable-normal trajectory, was associated with increased odds of pancreatic cancer in in males (OR: 2.58 ; 95\% CI 1.45 , 4.47) only, but not in females (OR: 0.55 ; $95 \%$ CI $0.21,1.42$ ) (Online Resource 1; Table 1). The progressively overweight and the progressive obesity trajectories had ORs greater than 1.0 in both males and females, possibly suggestive of increased odds of pancreatic cancer relative to the stablenormal weight trajectory; however, the results had very wide confidence intervals that overlapped 1.0 (Online Resource 1; Table 1). The persistent obesity trajectory results were hard to interpret separately in both males and females due to very small cell sizes and wide confidence intervals. When the results for BMI at each of the specific age periods were stratified by sex (Online Resource 1; Table 2), it appeared that the increased odds of pancreatic cancer associated with higher BMI was only present for males, but not females. Males with BMI $>30$ at each age period had increased risk of pancreatic cancer, this was the strongest for young adulthood (OR: 2.69; 95\% CI 1.22, 5.90) and mid-adulthood (OR: 2.30; 95\% CI 1.32, 4.01). Among females, all of the estimates had wide confidence intervals (overlapping 1.0) but many of the OR were less than 1.0 which is inconsistent with the hypothesis that overweight and obesity are associated with pancreas cancer risk.

\section{Discussion}

The results of this study contribute to the growing body of literature that describe life-course BMI trajectories and the association with pancreatic cancer. When BMI during each period of life was evaluated separately, the strongest associations with pancreatic cancer emerged in young and midadulthood. Further, five distinct trajectories of BMI across the life-course were identified and the persistent overweight and progressive obesity trajectories had ORs greater than 1.0 suggestive of increased risk. It is interesting that the magnitude of the ORs were greatest in the persistent overweight category which was characterized by higher BMI in the teenage years. The results for the persistent obesity trajectory, characterized by the highest BMI across the life-course, were somewhat unexpected in that the OR for the association with pancreatic cancer was less than 1.0; however, the number of participants in this trajectory was small $(2 \%)$ and the $95 \%$ CI was very wide. Evaluation of the characteristics associated with each trajectory among controls only showed that individuals in the persistent obesity trajectory were less likely to be in the older age group. Even though we adjusted for age group as a potential confounder (data on exact age were not accessible due to privacy regulations), it is possible 
Table 4 Odds ratio estimates for recalled body mass index (BMI) by age period and pancreatic cancer among cases diagnosed in 2011-2013 and controls recruited in 2011, from Ontario, Canada

\begin{tabular}{|c|c|c|c|c|c|c|c|c|c|c|}
\hline \multirow{2}{*}{$\begin{array}{l}\text { Body mass index }\left(\mathrm{kg} / \mathrm{m}^{2}\right) \\
\text { for various time periods }\end{array}$} & \multirow{2}{*}{$\begin{array}{l}\text { Cases }(n=310) \\
\mathrm{N}\end{array}$} & \multirow[t]{2}{*}{$\%$} & \multirow{2}{*}{$\begin{array}{l}\text { Controls } \\
(n=1,258) \\
\mathrm{N}\end{array}$} & \multirow[t]{2}{*}{$\%$} & \multicolumn{2}{|c|}{ Model 1} & \multicolumn{2}{|c|}{ Model 2} & \multicolumn{2}{|c|}{ Model 3} \\
\hline & & & & & $\mathrm{OR}^{\mathrm{a}}$ & $95 \% \mathrm{CI}$ & $\mathrm{OR}^{\mathrm{b}}$ & $95 \% \mathrm{CI}$ & $\mathrm{OR}^{\mathrm{c}}$ & $95 \% \mathrm{CI}$ \\
\hline \multicolumn{11}{|l|}{ Adolescent $^{\mathrm{d}}$} \\
\hline$<25.0$ & 246 & 80 & 1052 & 84 & 1.00 & & 1.00 & & 1.00 & \\
\hline$\geq 25.0$ & 49 & 16 & 188 & 15 & 1.13 & $0.81,1.63$ & 1.18 & $0.81,1.72$ & 1.16 & $0.79,1.71$ \\
\hline Missing & 15 & 4 & 18 & 1 & & & & & & \\
\hline \multicolumn{11}{|l|}{ Young adulthood (20 s) } \\
\hline$<25.0$ & 229 & 74 & 927 & 74 & 1.00 & & 1.00 & & 1.00 & $0.70,1.42$ \\
\hline $25.0-<30.0$ & 61 & 20 & 266 & 21 & 0.97 & $0.70,1.35$ & 0.96 & $0.68,1.36$ & 0.99 & $0.70,1.42$ \\
\hline$\geq 30.0$ & 17 & 5 & 53 & 4 & 1.47 & $0.83,2.61$ & 1.29 & $0.69,2.43$ & 1.11 & $0.58,2.15$ \\
\hline Missing & 3 & 1 & 12 & 1 & & & & & & \\
\hline \multicolumn{11}{|l|}{ Mid-adulthood (30-40 s) } \\
\hline$<25.0$ & 161 & 52 & 700 & 56 & 1.00 & & 1.00 & & 1.00 & \\
\hline $25.0-<30.0$ & 103 & 33 & 390 & 31 & 1.24 & $0.93,1.66$ & 1.27 & $0.93,1.74$ & 1.23 & $0.89,1.68$ \\
\hline$\geq 30.0$ & 43 & 14 & 155 & 12 & 1.39 & $0.94,2.06$ & 1.50 & $0.98,2.28$ & 1.39 & $0.90,2.14$ \\
\hline Missing & 3 & 1 & 4 & 0.3 & & & & & & \\
\hline \multicolumn{11}{|l|}{ Late adulthood (50-60 s) } \\
\hline$<25.0$ & 103 & 33 & 374 & 30 & 1.00 & & 1.00 & & 1.00 & \\
\hline $25.0-<30.0$ & 109 & 35 & 461 & 37 & 0.63 & $0.36,1.12$ & 0.91 & $0.65,1.27$ & 0.89 & $0.63,1.25$ \\
\hline$\geq 30.0$ & 75 & 24 & 255 & 20 & 0.91 & $0.67,1.24$ & 1.20 & $0.82,1.76$ & 1.10 & $0.74,1.64$ \\
\hline Age not reached & 21 & 7 & 163 & 13 & & & & & & \\
\hline Missing & 2 & 0.6 & 1 & 0.8 & & & & & & \\
\hline
\end{tabular}

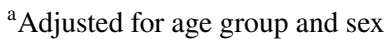

${ }^{b}$ Adjusted for age group, sex, race, alcohol consumption, smoking, vegetable consumption, fruit consumption, red meat consumption, current moderate physical activity, current vigorous physical activity, family history of pancreatic cancer

${ }^{\mathrm{c}}$ Adjusted for the variables in Model 2 with the addition of pancreatitis, diabetes

${ }^{\mathrm{d}} \mathrm{BMI}$ categories $25.0-<30.0$ and $\geq 30.0$ were collapsed for the adolescent time period due to small cell sizes when BMI $\geq 30.0$ was evaluated alone

that there is unmeasured or residual confounding by age. It may also be possible individuals in the persistent obesity group are less likely to be diagnosed with pancreatic cancer, due to earlier mortality from other diseases such as cardiovascular disease.

The five distinct life-course BMI trajectories that we identified are consistent with previous studies of similar methodologies. The Nurses' Health and Health Professionals Follow-up Study [21] and the Young Finns Study [42] both identified five trajectories describing body shape/BMI. However, the Young Finns Study identified a resolving obesity trajectory where the participants became a healthy BMI later in life. These studies include data prior to the teenage years unlike the data included within our study. Both studies, along with our findings identified the persistent obesity trajectory to have the smallest sample size. Understanding the life-course trajectories is important, as in our study population four of the five identified trajectories led to overweight or obesity in later adulthood. However, each revealed very different patterns of how overweight and obesity developed.
These details would not be perceptible in studies that only evaluate exposure in older life. Further, in our descriptive analyses of characteristics across trajectories it is apparent that there are unique distinctions.

Few studies have evaluated the effect of BMI before age $18[11,20]$ or life-course trajectories of body shape [21] and pancreatic cancer risk. Consistent with our findings, studies have identified an increased risk of pancreatic cancer in people who were overweight or obese during their adolescence [18, 20, 46-48]. Specifically, a prospective cohort study that followed participants for an average of 23 years, found men and women who were obese during ages 16-19 to be more likely to develop pancreatic cancer (HR: 3.67; 95\% CI 2.52, 5.34 for men; HR:4.07; 95\% CI 1.78, 9.29 for women) [20]. There is also evidence supporting an association between people with overweight and obesity in adulthood and pancreatic cancer risk [11, 12, 47, 48]. A pooled analysis [48] of 14-cohort studies in the Japanese population found an association between men aged 40 and above with obesity and pancreatic cancer (HR: 1.71; 95\% CI 1.03-2.86). 
A systematic review [14] that evaluated BMI and incidence of cancer found higher BMI in adults to increase pancreatic cancer risk from 16 prospective datasets (RR:1.07 95\% CI $0.93,1.23$ per $5 \mathrm{~kg} / \mathrm{m}^{2}$ in men; RR:1.12; 95\% CI 1.03, 1.23 per $5 \mathrm{~kg} / \mathrm{m}^{2}$ in women). Some results in our study are consistent with these, as we identified ORs ranging from 1.20 to 1.50 for participants with overweight and obesity during the 30-40 s, but our results did not provide evidence of an association between overweight and obesity in the 50-60 s and pancreatic cancer risk.

Song et al., studied trajectories of body shape across the life-course and the risk of pancreatic cancer. It was noted that those who were in the heavy-stable and increasingly heavy body shape trajectory had an increased risk of pancreatic cancer (RR: 1.39; 95\% CI 0.91, 2.12) [21] in comparison to those who were lean-stable throughout the life-course. These results are consistent with what we have found, as those who were in the progressive obesity group had an increased risk of pancreatic cancer (OR: 1.49; 95\% CI 0.77, 2.87). Levi et al. found an increased risk of pancreatic cancer in individuals who were overweight in adolescence using Cox proportional hazards modeling (HR: 2.09 ; $95 \%$ CI 1.26, 3.50) [20], which also aligns with our study findings.

Our study had limited statistical power to evaluate subgroups, however, the results of our stratified analysis by sex suggest that there may be differences in both the BMI trajectories and age-specific BMI categories in males and females. While strong increased associations with earlier life overweight and obesity were consistently observed among males, these associations were not observed among females. This is not consistent with one previous study that evaluated life-course BMI trajectories and pancreatic cancer risk [21] and previous reviews of later adult BMI and pancreas cancer have not reported sex differences [12]. It is possible that our results may be due to measurement error or information bias if females recall early life BMI differently than males. It is a limitation of our study that BMI was collected based on self-reported recall of early life weight. However, in epidemiologic research, using self-reported recall of BMI may be the most feasible option. Few historical records of weight exist limiting the potential of retrospective cohort studies and it is often not feasible to conduct a prospective cohort study from early life to late adulthood $[49,50]$. Several studies have investigated the validity of self-reported recall of early life BMI compared to prospective measurement or historical records, and relatively high correlation has been found $(r=0.74-0.84)[32,33,37,51]$. A recent systematic review found self-reported recall of past weight and prospectively measured weight had a small mean difference $(0.87 \mathrm{~kg} ; 95 \%$ CI $0.19-1.56)$ and was highly correlated (pooled $\mathrm{r}=0.83 ; 95 \%$ CI $0.72-0.90$ ). [30] There were small mean differences reported across studies that assessed the validity of self-reported recall and reference measures of
BMI [32, 33, 37, 51, 52]. Must et al. [33] found males underreported past BMI by $0.4 \mathrm{~kg} / \mathrm{m}^{2}$ and females underreported past BMI by $1.30 \mathrm{~kg} / \mathrm{m}^{2}$ across a mean period of recall of 55 years. Although self-reported recall of early life BMI or body fatness may be a valid measure, there are always limitations and potential biases from the use of BMI as a measure of obesity [53]. A limitation of this study may also be the broad age ranges for which participants were asked to recall their BMI, the questionnaires did not ask participants to report for exact ages. Since the questionnaire that was used to capture this information did not specify the exact years of age for this period, participants may have recalled their body size for different ages due to the broad nature of the question. Inadequate data on date of diabetes and pancreatitis diagnosis and duration of disease are another limitation of this study. Future research may further explore the impact of these factors on life-course BMI trajectories and risk of pancreatic cancer.

Strengths of this study include the population-based sampling strategy used to recruit cases and controls. The detailed nature of the questionnaire allowed for a comprehensive assessment of weight across the life-course and a wide range of potential confounders, including smoking and physical activity. Although we comprehensively assessed known pancreatic cancer risk factors, there still may be residual confounding due to measurement error or by other unmeasured confounders. Further, while we assessed BMI across four time periods, we did not have available data on early life BMI (prior to teenage years) which may limit the findings of this study. Without this data, evaluating a sensitive period of growth and development that impact risk of pancreatic cancer may be limited.

As with all case-control studies, a potential limitation of this study is recall bias. Survival bias may be a concern with this study since the outcome of interest is a high fatality disease. Every effort was made to reduce survival bias by recruiting cases shortly after diagnosis through the Ontario Cancer Registry's rapid-case ascertainment system. However, we can not rule out the possibility of survival bias, particularly with respect to the inconsistent findings for the persistent obesity trajectory if the cases with persistent obesity who participated in this study are systematically different from other adults with persistent obesity. While the low response rate and possibility of sampling bias may also threaten study validity, it was observed that most established pancreas cancer risk factors were associated with disease in the expected direction. Future studies would benefit from a larger sample size with additional statistical power to evaluate effect modification and potential interactions of sex, and possibly other factors such as smoking status, with each BMI trajectory.

The results from this study suggest BMI trajectories across the life-course are differentially associated with 
pancreatic cancer risk. Understanding the cumulative effect of BMI across the life-course may inform early life obesity prevention in turn reducing the burden of disease associated with pancreatic cancer.

Funding This work was supported by the Canadian Institutes of Health Research [Grant \# MOP-106631 to MC and Grant \# AO2-151560 to LNA] (http://www.cihr-irsc.gc.ca) and the National Institutes of Health [RO1 CA97075 to SG, as part of PACGENE consortium] (http://www. nih.gov). The funders had no role in study design, data collection and analysis, decision to publish, or preparation of the manuscript.

Data availability statement Data are available from the Ontario Pancreas Cancer Study and Ontario Cancer Risk Factor Study; however, access restrictions apply (data transfer agreement required by Cancer Care Ontario, and REB approval would be required). Authors Steven Gallinger and Michelle Cotterchio may be contacted for any requests at steven.gallinger@uhn.ca and michelle.cotterchio@ cancercare.on.ca.

\section{Compliance with ethical standards}

Conflict of interest The authors declare that they have no potential conflicts of interest.

Open Access This article is distributed under the terms of the Creative Commons Attribution 4.0 International License (http://creativeco mmons.org/licenses/by/4.0/), which permits unrestricted use, distribution, and reproduction in any medium, provided you give appropriate credit to the original author(s) and the source, provide a link to the Creative Commons license, and indicate if changes were made.

\section{References}

1. Canadian Cancer Society's Advisory Committee on Cancer Statistics. Canadian Cancer Statistics. Toronto, ON2015

2. Canadian Cancer Society's Advisory Committee on Cancer Statistics. Canadian Cancer Statistics 2017. Toronto, ON2017

3. Bray F, Ferlay J, Soerjomataram I, Siegel R, Torre L, Jemal A (2018) Global Cancer Statistics 2018: GLOBOCAN estimates of incidence and mortality worldwide for 36 cancers in 185 countries. CA Cancer J Clin. https://doi.org/10.3322/ caac. 21492

4. Siegel RL, Miller KD, Jemal A (2018) Cancer statistics, 2018. CA Cancer J Clin 68(1):7-30

5. American Cancer Society (2018) Key statistics for pancreatic cancer. American Cancer Society, New York

6. Maisonneuve P, Lowenfels AB (2015) Risk factors for pancreatic cancer: a summary review of meta-analytical studies. Int J Epidemiol 44(1):186-198

7. Anderson LN, Cotterchio M, Gallinger S (2009) Lifestyle, dietary, and medical history factors associated with pancreatic cancer risk in Ontario, Canada. Cancer Causes Control 20(6):825-834

8. World Cancer Research Fund/American Institute for Cancer Research (2012) Continuous update project report. Food, nutrition, physical activity and the prevention of pancreatic cancer

9. Lauby-Secretan B, Scoccianti C, Loomis D, Grosse Y, Bianchini F, Straif K et al (2016) Body fatness and cancer-viewpoint of the IARC working group. N Engl J Med 375(8):794-798
10. Michaud DS, Giovannucci E, Willett WC, Colditz GA, Stampfer MJ, Fuchs CS (2001) Physical activity, obesity, height, and the risk of pancreatic cancer. JAMA 286(8):921-929

11. Li D, Morris JS, Liu J, Hassan MM, Day RS, Bondy ML et al (2009) Body mass index and risk, age of onset, and survival in patients with pancreatic cancer. JAMA 301(24):2553-2562

12. Aune D, Greenwood DC, Chan DS, Vieira R, Vieira AR, Navarro Rosenblatt DA et al (2012) Body mass index, abdominal fatness and pancreatic cancer risk: a systematic review and non-linear dose-response meta-analysis of prospective studies. Ann Oncol 23(4):843-852

13. Genkinger JM, Spiegelman D, Anderson KE, Bernstein L, van den Brandt PA, Calle EE et al (2011) A pooled analysis of 14 cohort studies of anthropometric factors and pancreatic cancer risk. Int J Cancer 129(7): 1708-1717

14. Renehan AG, Tyson M, Egger M, Heller RF, Zwahlen M (2008) Body-mass index and incidence of cancer: a systematic review and meta-analysis of prospective observational studies. Lancet 371(9612):569-578

15. Rodd C, Sharma AK (2016) Recent trends in the prevalence of overweight and obesity among Canadian children. CMAJ 188(13):E313-E320

16. Genkinger JM, Kitahara CM, Bernstein L, Berrington de Gonzalez A, Brotzman M, Elena JW et al (2015) Central adiposity, obesity during early adulthood, and pancreatic cancer mortality in a pooled analysis of cohort studies. Ann Oncol 26(11):2257-2266

17. Eberle CA, Bracci PM, Holly EA (2005) Anthropometric factors and pancreatic cancer in a population-based case-control study in the San Francisco Bay area. Cancer Causes Control 16(10):1235-1244

18. Urayama KY, Holcatova I, Janout V, Foretova L, Fabianova E, Adamcakova $\mathrm{Z}$ et al (2011) Body mass index and body size in early adulthood and risk of pancreatic cancer in a central European multicenter case-control study. Int J Cancer 129(12):2875-2884

19. Patel AV, Rodriguez C, Bernstein L, Chao A, Thun MJ, Calle EE (2005) Obesity, recreational physical activity, and risk of pancreatic cancer in a large US cohort. Cancer Epidemiol Biomarkers Prev 14(2):459-466

20. Levi Z, Kark JD, Afek A, Derazne E, Tzur D, Furman M et al (2012) Measured body mass index in adolescence and the incidence of pancreatic cancer in a cohort of 720,000 Jewish men. Cancer Causes Control 23(2):371-378

21. Song M, Willett WC, Hu FB, Spiegelman D, Must A, Wu K et al (2016) Trajectory of body shape across the lifespan and cancer risk. Int J Cancer 138(10):2383-2395

22. Song M, Hu FB, Wu K, Must A, Chan AT, Willett WC et al (2016) Trajectory of body shape in early and middle life and all cause and cause specific mortality: results from two prospective US cohort studies. BMJ 353:i2195

23. Roberts KC, Shields M, de Groh M, Aziz A, Gilbert JA (2012) Overweight and obesity in children and adolescents: results from the 2009 to 2011 Canadian health measures survey. Health Rep 23(3):37-41

24. Carroll M, Navaneelan T, Bryan S, CL Ogden (2015) Prevalence of obesity among children and adolescents in the United States and Canada: US Department of Health and Human Services, Centers for Disease Control and Prevention, National Center for Health Statistics

25. Nader PR, O’Brien M, Houts R, Bradley R, Belsky J, Crosnoe R et al (2006) Identifying risk for obesity in early childhood. Pediatrics 118(3):e594-e601

26. Adamo KB, Ferraro ZM, Brett KE (2012) Can we modify the intrauterine environment to halt the intergenerational cycle of obesity? Int J Environ Res Public Health 9:1263-1307 Switzerland

27. Karaolis-Danckert N, Buyken AE, Kulig M, Kroke A, Forster J, Kamin W et al (2008) How pre- and postnatal risk factors modify 
the effect of rapid weight gain in infancy and early childhood on subsequent fat mass development: results from the multicenter allergy study 90. Am J Clin Nutr 87(5):1356-1364

28. Cunningham SA, Kramer MR, Narayan KM (2014) Incidence of childhood obesity in the United States. N Engl J Med 370(5):403-411

29. Cotterchio M, Lowcock E, Hudson TJ, Greenwood C, Gallinger S (2014) Association between allergies and risk of pancreatic cancer. Cancer Epidemiol Biomarkers Prev 23(3):469-480

30. De Rubeis V, Bayat S, Griffith L, Smith B, Anderson L (2018) Validity of self-reported recall of early life adiposity: a systematic review and meta-analysis. Obes Rev. https://doi.org/10.1111/ obr.12881

31. Kovalchik S (2009) Validity of adult lifetime self-reported body weight. Public Health Nutr 12(8):1072-1077

32. Troy LM, Hunter DJ, Manson JE, Colditz GA, Stampfer MJ, Willett WC (1995) The validity of recalled weight among younger women. Int J Obes Relat Metab Disord 19(8):570-572

33. Must A, Willett WC, Dietz WH (1993) Remote recall of childhood height, weight, and body build by elderly subjects. Am J Epidemiol 138(1):56-64

34. Bayomi DJ, Tate RB (2008) Ability and Accuracy of Long-term Weight Recall by Elderly Males: the Manitoba Follow-up Study. Ann Epidemiology. 18:36-42

35. Perry GS, Byers TE, Mokdad AH, Serdula MK, Williamson DF (1995) The validity of self-reports of past body weights by US adults. Epidemiology 6(1):61-66

36. Casey VA, Dwyer JT, Berkey CS, Coleman KA, Gardner J, Valadian I (1991) Long-term memory of body weight and past weight satisfaction: a longitudinal follow-up study. Am J Clin Nutr 53(6):1493-1498

37. Norgan NG, Cameron N (2000) The accuracy of body weight and height recall in middle-aged men. Int J Obes Relat Metab Disord 24(12):1695-1698

38. de Onis M, Habicht JP (1996) Anthropometric reference data for international use: recommendations from a World Health Organization Expert Committee. Am J Clin Nutr 64(4):650-658

39. Andruff H, Carraro N, Thompson A, Gaudreau P, Louvet B (2009) Latent class growth modelling: a tutorial. Quant Methods Psychol $5(1): 11-24$

40. Jones A (2017) Traj: group-based modeling of longitudinal data. Carneige Mellon University, Pennsylvania

41. Howe CJ, Cole SR, Lau B, Napravnik S, Eron JJ (2016) Selection bias due to loss to follow up in cohort studies. Epidemiology 27(1):91-97

42. Buscot MJ, Thomson RJ, Juonala M, Sabin MA, Burgner DP, Lehtimäki T et al (2018) Distinct child-to-adult body mass index trajectories are associated with different levels of adult cardiometabolic risk. Eur Heart J 39(24):2263-2270

43. Albaum JM, Carsley S, Chen Y, Dai DWH, Lebovic G, McCrindle BW et al (2017) Persistent high non-high-density lipoprotein cholesterol in early childhood: a latent class growth model analysis. J Pediatr 191:152-157

44. SAS Institute Inc. SAS. 9.4 ed 2018

45. Rahman F, Cotterchio M, Cleary SP, Gallinger S (2015) Association between alcohol consumption and pancreatic cancer risk: a case-control study. PLoS ONE 10(4):e0124489

46. Zohar L, Rottenberg Y, Twig G, Katz L, Leiba A, Derazne E et al (2019) Adolescent overweight and obesity and the risk for pancreatic cancer among men and women: a nationwide study of 1.79 million Israeli adolescents. Cancer 125(1):118-126

47. Stolzenberg-Solomon RZ, Schairer C, Moore S, Hollenbeck A, Silverman DT (2013) Lifetime adiposity and risk of pancreatic cancer in the NIH-AARP diet and health study cohort. Am J Clin Nutr 98(4):1057-1065

48. Koyanagi YN, Matsuo K, Ito H, Tamakoshi A, Sugawara Y, Hidaka A et al (2018) Body-mass index and pancreatic cancer incidence: a pooled analysis of nine population-based cohort studies with more than 340,000 Japanese subjects. J Epidemiol 28(5):245-252

49. Batty GD, Calvin CM, Brett CE, Čukić I, Deary IJ (2015) Childhood body weight in relation to morbidity from cardiovascular disease and cancer in older adulthood: 67-year follow-up of participants in the 1947 Scottish Mental Survey. Am J Epidemiol 182(9):775-780

50. Casey VA, Dwyer JT, Coleman KA, Krall EA, Gardner J, Valadian I (1991) Accuracy of recall by middle-aged participants in a longitudinal study of their body size and indices of maturation earlier in life. Ann Hum Biol 18(2):155-166

51. Koprowski C, Coates RJ, Bernstein L (2001) Ability of young women to recall past body size and age at menarche. Obes Res 9(8):478-485

52. Jenkins TM, Buncher CR, Akers R, Daniels SR, Lawson ML, Khoury PR et al (2013) Validation of a weight history questionnaire to identify adolescent obesity. Obes Surg 23(9):1404-1412

53. Rothman KJ (2008) BMI-related errors in the measurement of obesity. Int J Obes (Lond) 32(Suppl 3):S56-S59

Publisher's Note Springer Nature remains neutral with regard to jurisdictional claims in published maps and institutional affiliations. 